\title{
The Legal and Economic Support of Mutual Aid Pension Model Based on Acquaintance Relationships
}

\author{
Zhihua Song \\ Department of Public Administration \\ Tianjin Vocational Institute \\ Tianjin, China \\ Songzhihua83@126.com
}

\begin{abstract}
The mutual aid pension model has emerged based on social acquaintance relationships. It makes the family harmonious, overcomes the lack of resource in elders' families, reduces the pressure of social pension and provides better service for the elderly in their old ages. It is an effective way to reduce the pressure of social pension. Government and society should give policy support in terms of organizational support, event counseling, economic subsidies, welfare benefits and provision of places.
\end{abstract}

Keywords-acquaintance society, mutual aid pension, policy support

\section{INTRODUCTION}

At present, China's social pension models are mainly three models: family pension, community home pension, institutional pension. A pension model based on acquaintance social relationship is spontaneously formed. This paper studies this model and puts forward corresponding suggestions for its corresponding legal and economic support.

\section{Conceptions of Mutual Aid Pension Model}

\section{A. Acquaintance society}

In $20^{\text {th }}$ century, Xiaotong Fei pointed out that Chinese society is an acquaintance society[1] in his book "From the Soil”. This tells the reality of Chinese social relations. This is an important reference point for solving all the actual problems of Chinese society because it penetrates all areas of Chinese society. The reason for the formation of acquaintance society is mainly due to the economic base of small peasants in Chinese society. In such a self-sufficient small-scale economic society, people pursue living and working in peace. They are longing and accustomed to long-term sticking to one side, so a stable interpersonal relationship is formed-acquaintance relationship. Acquaintance society is formed based on acquaintance relationship. Members of the society are inextricably linked, including blood relationships, friends, neighborhoods, fellow, and even people from the same area. After the founding of new China, this relationship has not fundamentally changed.

The nature of acquaintance society is that there is a personal relationship between people. People are linked through this relationship and this builds a network of relationships. Background and relationship are typical essentials of acquaintance society. These form an emotional or interest groups based on acquaintance relationship.

\section{B. The mutual aid pension model}

Mutual support pension is a positive, civil, low-cost pension service model, which rises in the country gradually. It becomes an important supplement for family pension, community pension, and institutional pension.[2] Mutual aid pension model in this paper is spontaneously formed based on acquaintance relationships. It has the following three models:

Model A: Based on the relationship between blood relationship and direct relationship, this pattern exists in ancient times. The charitable estate support in ancient China belongs to this form. It mainly takes the blood relationship as the link, charitable estate as the carrier, charitable fields as the basis, and forms the mutual aid pension among families. It can be seen that this is a pension mode naturally generated by our acquaintance society, and is one of our traditions. 6 years ago the country started to promote the trial of mutual aid pension model in rural areas. Ministry of Civil Affairs conducted a pilot rural mutual aid happy home in Hebei province. Since then, it is promoted throughout the country. The so-called blood relatives and friends in the paper include family, blood relationships, such as parents, brothers and sisters, and cousins. Today's elderly people who are over 65 years old, they have brothers and sisters, and most have several children, but not all around. Their children go to the city or other cities as young labor force for various reasons. Because they have many relatives, the mutual aid pension model is spontaneous formed. However, their children are still the main characters. The money is basically provided by themselves and children. Blood relatives will also provide some, but most of them are given as gifts. If an elderly person is disabled, his children provide the main care, but long-term care requires more human resources. So, friends and relatives have become the power of nursing. This kind of help is free. This kind of mutual assistance is particularly important in special times. Such as the occurring maintenance fee disputes, the elders' hospitalization, and funeral arrangements and so on. This mutual help is more common in the vast rural areas.

Model B: Based on colleagues, classmates, friends and other relations agreed to reach a mutual aid pension. At 
present, most low age elders have only one child. They are the first generation responding to "a pair of parents only have a child" policy. They only have one child and the child is in working period, so he doesn't have enough time to take care of his parents who are growing old. So, elders' colleagues, classmates, friends agree to live together in their later years. This kind of mutual aid pension model has some nature of the civil organization. They have charters and contracts. Besides, there are some rules and regulations to constrain the behavior of members to keep the organization running well. It's characterized by that the participants are mostly self-care elderly who have good physical condition. Mutual assistance is mostly in the short-term help, such as economic assistance, nursing, emergency assistance and so on. This relationship is mainly based on emotion, interest and so on.

The above two models are based on acquaintance relationships. Basically, in this mutual benefit relationship model, the affection is the core link. For mutual aid pension based on family, the relationship is relatively stable, but the scope is limited. For friendship-based mutual aid pension, the relationship is relatively weak, but the corresponding rules can maintain the constraint.

The development of the above two models will be merged. For example, the only child born after the 80s of last century, are facing with the burden of raising four or more elderly people. So, the children will group their elderly people with peers' elderly people. This mutual support model is based on their children's friend relationships. The elderly people themselves and their children provide the economic guarantee, so elderly people can take care each other when some elderly people are disabled or half disabled.

Model C: Based on the elderly in the same community. Mainly old neighborhoods in the countryside and urban spontaneously formed mutual support pension. And this model in rural areas is basically the same as model A. In the urban community, it's similar to community home pension. [3] The main difference is the elderly mutual aid is free, while the community services need to be paid.

\section{REASONS OF MUtUAL Aid PENSION MODEL DEVELOPMENT}

\section{A. Reduce the pressure of unprepared pension project}

With the rapid development of aging, the lack of social preparation has become more and more prominent. For example, Tianjin City, the city's social aging, ranked the forefront of China. By the end of 2015, the population aged over 60 occupies $22.43 \%$ of Tianjin's population, which is 230.37 million. Five years later, it will grow to 2.73 million, occupying more than $25 \%$ of the population. Professor Guangzong $\mathrm{Mu}$ in Institute of Population of Peking University pointed out that China's aging population increase rapidly, but pension service system is seriously lagging. The survey data provided by China Agricultural Science Research Center shows that by 2013, 16.6\% of Chinese disabled elderly people are willing to stay in the pension institutions. It means there are 5.976 million disabled elderly need to stay in the pension institutions, but the current amount of beds is seriously insufficient. Only about $15 \%$ private pension institutions can provide "rehabilitation care" services, far from the long-term demand of disabled elderly people. Elderly people health service resources are insufficient. At present, there are 61 National Elderly Hospitals. Among them, only one is threelevel hospitals, 19 two-level hospitals, 18 two-level hospitals, others are not rated hospitals. There are 265 hospitals are closely related elderly people health of which 219 are in urban areas, 46 in rural areas. China has 41 nursing homes, all located in urban areas, only 11 of them are county-level or above. There are 65 nursing stations in China. 59 of them are in urban areas, but rural areas only have 6. Apparently, the Chinese government and society are not ready to face the wave of age, leading to the serious problem of "aging before preparation". At present, the state has invested a lot in pension institutions, but the effect is very little. Two high-end pension agencies in Tianjin, each has an investment of billions of money. But because of its membership, the current occupancy rate is less than a thousand households, and they all are highend members, which do not help solve the pension demand of the widest majority of low-income elderly. Mutual aid pension model based on the relationship between acquaintances is a mutual support pension model based on huge social human resources and economic resources of family members, relatives and friends. It greatly reduces and alleviates the social pension pressure and "is a low-cost strategic choice to deal with the aging of the population." [4]

\section{B. In line with the traditional concept of pension and the rapid active aging trend}

According to the survey of the willingness of pension, $90 \%$ of the elderly in China like staying at home, $7 \%$ of them choose community pension, only $3 \%$ of them accept pension institutions. In fact, the proportion of home care is still higher. This is the inevitable reflection of the traditional concept of Chinese pension. In mutual aid pension model, the main place is home, along with some places for gatherings and activities; the main human resources are relatives, supplemented by the help of neighbors and friends. The advantages are that the elderly can enjoy family happiness at home and do not have psychological problems such as family abandonment. The elderly can do as much as they can for the family. This reduces their useless and inferiority feeling due to quitting from society production and it's conducive for the elderly to have a positive and optimistic life. Communicating with friends and relatives will further promote the social interaction of elderly people. It is not only conducive to overcome the elderly loneliness in his later years, but also maintain the family affection and friendship, helping to build the harmony in the community.

Mutual aid pension model is also consistent with the development trend of modern active aging. The concept of active aging was first proposed by the Denver Conference in 1997. The World Health Organization's explanation is the three basic dimensions of "health", "participation" and "security". Mutual aid pension model has the above three elements. Positive aging takes people's aging process as a positive and energetic process, advocating that older people should have a healthy life and have a chance to devote themselves to society. [5] In China's Old Age Career 
Development conference, "Tenth Five-Year Plan" outline pointed out that "Insist from the material and spiritual aspects to improve the quality of life of the elderly, guide the elderly to have a self-reliance and motivated life." [6] "Eleventh FiveYear Plan" outlines and "Thirteenth Five-Year Plan" outline reaffirmed this concept. Through the mutual aid pension practice, the elderly not only enhance their own value, but also effectively meet the requirements of some of the elderly care, at the same time, it also actively and comprehensively promote the sustainable development of the whole society. [7]

\section{Conducive to guarantee the rights and interests of the elderly}

On the one hand, mutual aid pension model can take care of elderly people. Meantime, the relationship between acquaintance also supervises whether the elderly children support their parents on time or not. This has positive significance to carry forward the traditional filial piety culture. On the other hand, the mutual assistance groups the elderly and their relatives and friends together. This is more powerful than single elder to maintain the rights of the elderly and prevent the infraction from family and society.

\section{Conducive to improving the quality of life of the elderly}

"2014 China's Elderly Social Follow-up Survey Report" shows that nearly a quarter of the elderly have varying degrees of loneliness, they need social interaction more. At the same time, the proportion of Chinese elderly people participating in social welfare activities is relatively low; the participation rate is only about $20 \%$. The reason is multifaceted, but the main reason is that there is no channel and activity is not suited to their own needs. Mutual aid based on the relationship between acquaintances establishes a platform for the elderly to have social interaction, so that they can have a certain sense of belonging, eliminating loneliness; conduct elderly cultural and recreational activities to enhance the enthusiasm of the elderly to participate in social activities, enriching their leisure life; conduct mutual support pension activities to achieve the value of the elderly themselves, and also affirm the meaning of the elderly life, which is the greatest spiritual comfort for the elderly. The above three positive roles of mutual aid pension based on the relationship between acquaintances will undoubtedly greatly promote the improvement of the quality of life of the elderly.

\section{LEGAL AND ECONOMIC ADVICE}

At present, mutual aid pension model based on acquaintance relationship, is created by the elderly themselves. It still inherits the "pension is a personal problem" concept, so it's urgent for government and society to support, guide, and even manage. However, the most existing support policies are about agency pension support, only a few of them support the family pension. To the social institutions pension, mutual aid pension model based on acquaintance relationship is a lowcost great-effect pension model. The government and society should give strong support.

\section{A. Legal support}

Mutual aid pension model is a new thing, so the legal help is necessary. Society should provide simple and convenient low-cost or even unpaid legal aid for the elderly.
On the organization level, the government and society should help the mutual aid elderly. It's necessary to clarify the legal nature of the organization and the legal obligations between members; regulate the content and methods of member activities; help them form some conventional regulations on management and operation. It should strengthen the guidance and organization, but not break their own integrity. It should be voluntary participation and always treat the elderly as the main body. Help the elderly to solve various problems, such as disputes, contradictions, etc. Use the form of law to require social workers to help solve the problems of the elderly, such as psychological problems, family problems, and modern life technology and held various forms of health benefits activities to safeguard the legitimate rights and interests of the elderly. The specific content of the relevant legal support should be researched and developed according to the needs of practice.

\section{B. Economic support}

The nation should apply the current support policy and subsidies measures to mutual aid pension model. Such as bed subsidies, training in nursing technology, social worker training, health literacy knowledge learning, etc. Increase the pension amount of the elderly who participate in the mutual aid pension activities. Make some favorable policies to support its development. For example, to the children who fulfill the obligation; reduce their corresponding personal income tax, property costs, and inheritance costs. Improve proportion of medical care reimbursement of the elderly if they participate in mutual aid pension model and build health records for them, etc. Increase the elderly activities space and construction funds. Increase the public space and public facilities to solve the problem of lacking space in mutual aid pension model.

\section{CONCLUSION}

Mutual aid pension model is spontaneously created by the elderly. After strengthening the social and government support, it will become the elderly mutual aid pension model based on the similar quality of the elderly population and their relatives and friends. The elderly and their relatives are the main force. Relying on community resources, under the guidance and help of the society and government, the pension mode based on mutual aid of elderly will response to the rapid aging trend fast and effectively with very low costs. The government and society should give the necessary support and help. This is also a suitable pension way which fits Chinese situation.

\section{REFERENCE}

[1] Xiaotong Fei, “From the Soil”, Sep 2011 edition.

[2] Xin Liu, "The present situation and reflection of the practice of mutual aid pension model in China”, pp88, Modern Management Science. 2017-1-10

[3] Li Zhang, Tingting Qin, "Evaluation and analysis on community pension and community mutual aid pension”, Knowledge Economy, pp74, Feb 2014

[4] Yaya Hao, Hongxia $\mathrm{Bi}$, "the research of mutual aid pension model in rural areas in China”, pp 47, Aging Scientific Research 2017-02-25

[5] Junpu Zhang, "Evaluation and analysis about active aging in rural areas”, pp2, Fujian Agriculture and Forestry University Newspaper, 2017-1-5. 
[6] The State Council, China’s Old Age Career Development "Tenth FiveYear Plan" (2001-2005) outline, 2001-7-22

[7] Jinghui Yang, "Mutual aid pension model—rational choice in transition”, pp141, Lanzhou Journal, Sep 2014 